\title{
Practice in the Schools of Public Health
}

KathleEN WRight, EdD MPH

ELIZABETH WEIST, MA MPH

BARRY STERN, MPH

Promoting Academic Linkages in Public Health Practice: The ASPH Council of Public Health Practice Coordinators

\section{RAPID CHANGES IN THE FIELD OF PUBLIC HEALTH}

The field of public health, including the academic sector, is experiencing enormous challenges. All areas of public health, furthermore, are facing new stressors, such as evolving epidemics, changing infrastructure needs, and debate regarding the definitions of public health practice, the roles and competencies of providers, and the increasingly important requirements for linkages with community and agency partners. The academic sector is no exception.

\section{IMPROVING LINKAGES AND RELATIONSHIPS BETWEEN ACADEMIA AND PRACTITIONERS IN PUBLIC HEALTH}

For over a decade, the federal government and graduate schools of public health have been encouraging improved linkages among academic institutions, community organizations, and public health agencies. A major impetus for increased collaboration came from recommendations in several documents, including the 1988 Institute of Medicine (IOM) report, which identified a serious disconnect between academic and public health institutions.

In response, federal agencies, primarily the U.S. Public Health Service (PHS) through the Health Resources and Services Administration (HRSA) and Centers for Disease Control and Prevention (CDC), have provided support in the form of cooperative agreements and technical assistance to expand partnerships between schools of public health and various public health practice agencies to enhance the performance of public health services.

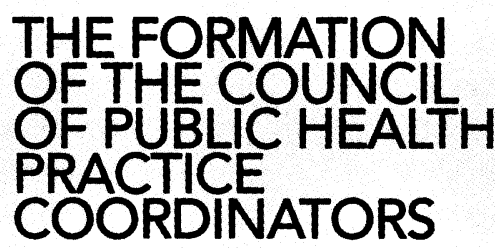

In 1992, the Association of Schools of Public Health (ASPH), to advance these efforts, established the Council of Public Health Practice Coordinators. The Council's purpose is to promote academic-practice linkages and a greater commitment to scholarship in public health practice-based research, teaching and service. Council members are

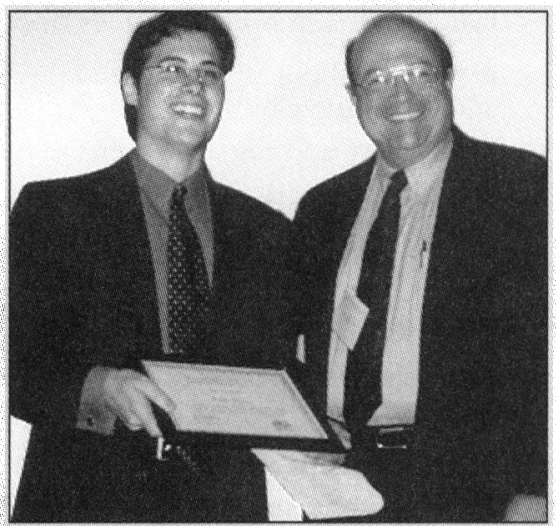

Nickolas Deluca, MA, with Dr. Carl W. Tyler, Jr, at ASPH awards ceremony.

designated practice coordinators from each of the 28 schools of public health who are typically administrators or faculty members having significant experience in the practice community and/or holding joint appointments in practice agencies.

The Council serves as a forum for identifying excellence in academic public health practice and for exploration of innovative methods to incorporate principles of public health practice within the research, teaching, and service agendas in the graduate schools of public health (SPH). Practice coordinators perform liaison functions, not only with official public health agencies (e.g., state and local health departments), but also with community-based health organizations, managed care organizations, and the federal government. The group also serves as a link for practitioners in the field to access resources and explore collaborative ventures with faculty and administra- 
tors in the SPH, and advises school deans on issues relevant to academic public health practice.

Support from the Bureau of Health Professions of HRSA and the Public Health Practice Program Office (PHPPO) of the CDC* has provided the Council with opportunities to examine scholarship, curricula, faculty and organizational issues related to excellence in practice-based research, teaching, and service.

Progress has been made toward expanding existing linkages with agencies and the community. For example, public health agencies benefit by receiving technical assistance in research and evaluation from the schools, while academic institutions gain from the practice sectors' involvement in the design and provision of education, training and field placement programs. This synergy among the SPH and practitioners results in more relevant education for students preparing for careers in the public health workforce and for continued development of the public health workforce to perform the essential services of public health.

Furthermore, communities and agencies benefit from the immediate contribution provided to them by the faculty and student interns/fellows and by the long-term expertise from students who decide to seek employment in their organizations upon graduation.

The Council schedules two to three meetings annually. One takes place during the fall ASPH and American Public Health Association meetings. Other annual meetings have occurred with support from HRSA and CDC. For example, for several years the CDC-sponsored Council meetings in conjunction with the CDC Partnering Meeting, and HRSA- supported annual conferences have assisted the Council in further defin-

ing its objectives and advancing progress on its agendas.

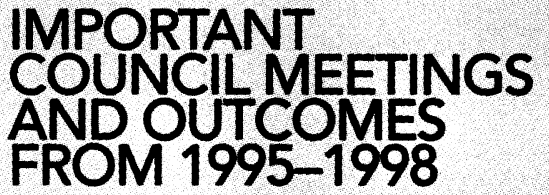

Each year, HRSA-supported workshops have been co-sponsored by a school of public health. The 1995 meeting, held in Columbia, South Carolina, focused on models of innovative practice activities, deliberations on the definition and future of public health practice, and the roles of ASPH practice coordinators. In 1996, the meeting was held in Boston, Massachusetts to continue work on examining the barriers and obstacles to further achieving academic public health practice objectives in schools of public health. As a result, the Council established a set of benchmark indicators of barriers to progress and recommendations to reduce them.

The "Barriers Chart" has since been used by the Council to sustain momentum and monitor progress towards accomplishing annual objectives. Several barriers, or areas needing improvement, were identified, and many of these have been addressed through subsequent meetings and designated work group activities. They include the need to: 1) develop a definition of scholarship and practice; 2) promote faculty incentives and commitment to practice; 3) support the development of practice-based case studies and curriculum improvement; 4) advance leadership development and practice; 5) assess workforce capacity, skill and competency needs; 6) measure community health status and needs; and, 7) support managed care and curriculum development.

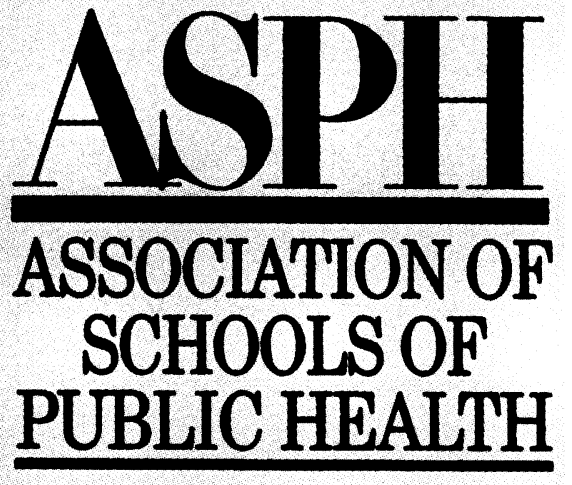

In 1996, the Practice Council assigned a work group to intensify efforts to address "barriers" one and two, listed above, including review of the academic role in public health practice and the role of practice in academia. Furthermore, in the same year, HRSA sponsored a meeting of the workgroup in Savannah, Georgia, to begin efforts required to complete a Council document entitled Demonstrating Excellence in Academic Public Health Practice. Additionally, in relation to these same objectives, another Council workgroup was established to create an annual awards program to identify and reward significant accomplishments by faculty, practitioners, and students in academic public health practice. The CDC-sponsored Carl W. Tyler, Jr Award for Excellence in Public Health Practice was initiated this year to honor the retirement of Dr. Tyler from outstanding and dedicated public health service while he was assistant director for academic programs at PHPPO.

This year's award recognized student achievement, and the first recipient of the award was Nickolas DeLuca, MA, who is an ASPH/ CDC/ATSDR Public Health System Fellow at the National Center for HIV, STD, and TB Prevention in the Division of Tuberculosis Elimination. Nick is concurrently 
pursuing a $\mathrm{PhD}$ in Health Education and Health Promotion at the University of Alabama at Birmingham. It is anticipated that annual awards will be launched in the fall of $\mathbf{1 9 9 9}$ for faculty and practitioners, in addition to students, who demonstrate exceptional collaboration and practice in the field of public health.

Other "barriers," e.g, four and five, listed above, were also addressed through practice coordinators serving as liaisons with other organizations and as advocates for federal support of special projects and cooperative agreements through ASPH. Several Council members, for example, have served as advocates for the development of CDC and PHPPO-sponsored national, regional and state-based public health leadership institutes, including establishment of the National Public Health Leadership Development Network and ASPH-proposed development of the Public Health Practice Training Centers.

Most recently, the Council met in 1998, in Ann Arbor, Michigan to discuss developments in scholarly community-based academic public health practice. The meeting provided the opportunity for the Council to focus on models of community-based practice research, teaching and service. Partnerships between the University of Michigan School of Public Health and the local community were highlighted through participation of Council members with local academic, practice and community partners in field visits to explore dimensions of academic public health practice in the community setting. This portion of the meeting served to complement and enhance deliberations by the Council during the remainder of the meeting regarding the presentation and building of consensus on a draft of a Council's document to define academic public health practice.

\section{DEVELOPMENT OF A LANDMARK DOCUMENT}

Demonstrating Excellence in Academic Public Health Practice represents the first attempt by the academic public health community to define the scope of academic public health practice, further illuminate the role of schools of public health in helping to assure the performance of the essential services of public health, and address evaluation and incentives for faculty who perform, with practice partners, scholarly practice-based research, teaching and service activities. This publication should serve as a valuable document in promoting and advocating for greater visibility and recognition for the role of the academy as a partner in public health practice.

\section{COUNCIL DIRECTIONS IN THE PROMOTION OF ACADEMIC PUBLIC HEALTH PRACTICE}

The ASPH Council of Public Health Practice Coordinators will continue to support efforts to enhance academic public health practice. The Council views practice as a major force contributing to the discovery and application of new knowledge to pub- lic health through the creation and promotion of partnerships among students, faculty, community groups, and other health organizations and agencies.

Although each SPH has followed its own path towards the institutionalization of public health practice within its walls and in connecting with agencies and communities, the schools as a whole have made tremendous progress in the seven years since the Council was created. The unique differences in history, orientation, culture and resources among schools have contributed to variations in how SPH are creating and sustaining partnerships with other organizations and their communities to assure provision of essential health services and to improve health and the quality of life. In order to meet the needs of the next generation, the Council understands that it must communicate effectively among vested groups and build on best models in order to construct a shared future of effective public health practice.

\footnotetext{
*The Council wishes to acknowledge Edward Baker, MD, MPH, Director, Public Health Practice Program Office at the $C D C$, and Ronald Merrill, MHA, Chief, Public Health and Dental Education Branch at the Bureau of the Health Professions, HRSA for their support of Council activities.

Dr. Wright is chair of the ASPH Council of Public Health Practice Coordinators. Ms. Weist is director of education and practice programs at ASPH. Capt. Stern is a HRSA Project Officer.
} 